\title{
A Study on Assessing the Potential and Use of Mobile Phones by Farmers in Nellore District of Andhra Pradesh
}

\author{
D. Vinod Naik ${ }^{1 *}$, M. Kavitha ${ }^{2}$ and R.V.S.K. Reddy ${ }^{3}$
}

${ }^{1}$ Agril. Extension, Krishi Vigyan Kendra, Periyavaram, Venkatagiri, SPSR Nellore Dist, A.P, India

${ }^{2}$ Krishi Vigyan Kendra, Periyavaram, Venkatagiri, SPSR Nellore Dist, A.P., India

${ }^{3}$ Dr. Y.S.R. Horticultural University, V.R. Gudem, A.P., India

*Corresponding author

\section{A B S T R A C T}

\begin{tabular}{|l|}
\hline Ke y w o r d s \\
$\begin{array}{l}\text { Advisory services, } \\
\text { Mobile telephony, } \\
\text { Respondents } \\
\text { Farming }\end{array}$ \\
\hline Article Info \\
\hline $\begin{array}{l}\text { Accepted: } \\
\text { 26 July 2019 } \\
\text { Available Online: } \\
\text { 10 August } 2019\end{array}$ \\
\hline
\end{tabular}

The agriculture sector benefits more from mobile phones in the developing countries as it saves money, time and offers accurate advantage for farmers. The mobile phone system can be used to alert villagers about disease outbreaks and other important agricultural information. Many of the farmers suffer from lack of up to date, accurate market price information because of their remote location, or simply because they don't know how and where to get trustworthy information. A study was undertaken to assess the potential and use of mobile phones by farmers. The study sample comprised of 120 farmers, selected randomly from the farmers visiting Krishi Vigyan Kendra, Periyavaram, SPSR Nellore District, A.P. The study indicates that $24.16 \%$ farmers owned a mobile for more than 3 years and 85.84 percent received information related to agriculture from farmers. All the respondents interviewed said that they would like to subscribe if KVK Periyavaram starts mobile based advisory service, although only $68.34 \%$ said that they would be willing to pay a nominal fee of Rs.100 per month. As regards the type of services expected through such a mobile service, farmers identified the areas - disease identification and control measures $(72.50 \%)$, Crop Variety recommended/appropriate $(53.33 \%$ ) and about Agronomic Practices (40.80 \%). Further, about 32.50 per cent of the respondents reported to be ready to receive the information regarding Sowing Time followed by Post-Harvest Operations $(18.33 \%)$ and Seed Treatment $(17.50 \%)$, Fertilizer Applications $(15.83 \%)$ and Marketing (11.66 \%). The study illustrates the need for a mobile based agri advisory services and possible policy implications for different stakeholders.

\section{Introduction}

Agriculture in India comprising of crops, dairy, fishery, horticulture, agro-forestry along with small enterprises like beekeeping, mushroom cultivation etc., needs the use of modern technologies to achieve the target growth. Need of the hour is to harness productivity along with sustainability, minimize post-harvest losses and getting appropriate prices for the produce. For this, extension has to play an expanded role including improved access to markets, research, advice, credit, infrastructure, development of farmer organizations and business development services (Sulaiman, 2003). The information and communication technologies like radio, TV, newspaper, telephones and magazines are playing a major role in sustainable agricultural development 
since early decades and now the modern information communication technologies (ICTs) as mobiles and computers have created a revolution. In the 21 st century, cost effective and efficient communication technologies are required to take lead in changing the agricultural scenario.

In recent years, there has been a rapid growth of mobile phone networks in developing countries. Most of the countries in the developing world have skipped fixed-line infrastructure and leapfrogged directly into mobile technology. Mobile phone is becoming one of the basic necessities now a day for all types of users irrespective of the age group. A mobile phone is an Information Communication Technology (ICT) tool used for two-way communication. Further, it helps to disseminate information, improve farmers' knowledge, increase their participation and share knowledge with others. Mobile phone has become more relevant in the modern days and agriculture is also one of the sectors benefited from it. In India mobile technology has unleashed a paradigm shift in the communication medium to reach out to the masses.

Information asymmetry acts as one of the major constraints on the growth of agricultural productivity in India. The rapid growth of mobile telephony as compared to fixed line telephony and the recent introduction of mobile-enabled information services provide a means to overcome existing information asymmetry. It also helps, at least partially, to bridge the gap between the availability and delivery of agricultural inputs and infrastructure.

The agriculture sector benefits more from mobile phones in the developing countries as it saves money, time and offers accurate advantage for farmers. The mobile phone system can be used to alert villagers about disease outbreaks and other important agricultural information. Many of the farmers suffer from a lack of up to date, accurate market price information because of their remote location, or simply because they don't know how and where to get trustworthy information. SMS is used to send out the data to groups of producers, government officials and others working in the agricultural sector, according to the type of information they require, which could be produced, prices of fertilizer and pesticides, or even weather forecasts. India is stimulating the potentials of ICTs in all spheres of development. To achieve the concept of education from all the cheapest media and modes of communication. The Mobile becomes the best, due to its easy accessibility and convenient handling, of course, the tool is highly reliable and enhances the scope of its utility, even among the petty business to elite groups use.

Mobile phones are tools that can help farmers to climb out of poverty. The mobile phone technology is being used creatively in poor countries to help spur development and reduce poverty, particularly in remote rural areas. Mobile phones are already being used in rural areas as a tool for financial transactions by swapping airtime for goods and services. Mobile networks and financial services institutions to work together to test and develop new financial services in this area and to address how people can transfer these credits into cash. Accessing information about public services remains a major challenge for many rural communities. Mobile phones provide a new platform through which rural communities will be able to access government information and services, using text, data, and audio browsing techniques.

There are many researchable questions that need to be answered such as: Are mobile phones in practice being used for agricultural purposes, and if so, how? Have mobile phones 
helped in driving Improvement in agricultural productivity of farmers and if so, how? Which types of agricultural information are of high value for farmers? What are the constraints to the potential use of mobile phones in improving agricultural productivity? What type of problems do you encounter in the use of mobile phone? Whom do farmers contact and how frequently for agricultural information?

The answers to these questions have important implications for mobile phone operators, information service providers, and policymakers.

The present study entitled A Study on Assessing the Potential and use of Mobile phones by farmers in Nellore District of Andhra Pradesh was undertaken with the specific objectives: (a) to find the sociopersonal characteristics of the mobile user farmers, (b) to determine the utilization pattern of use of mobile phone among the farmers, and (c) to find out the extent of use of mobile for seeking agricultural information by farmers

\section{Materials and Methods}

The study was conducted at Krishi Vigyan Kendra, Periyavaram, Venkatagiri, SPSR Nellore District of Andhra Pradesh. The study sample comprised of 120 farmers, selected randomly from the daily register of visiting farmers who got themselves registered with detailed information. Many farmers from different villages of different mandals used to visit KVK. An exploratory research design was used. Socio economic characteristics included age of the respondent, gender, education, occupation, type of family, family size, family occupation, type of house, landholding and type of farming. Besides, ability to use the mobile phone, regularity, cost and benefits, ability to understand the message, trust in the information etc. were included to assess the utility and potential of mobile in farming. The data was collected through personal interview using a structured interview schedule. The data, collected was analysed using appropriate statistical tools. The scales used in socio economic characteristics were taken from different sources

\section{Results and Discussion}

The study was conducted to find out the socioeconomic profile of the users of the mobile phones for obtaining agricultural information. It is clear from table 1 that more than half of the respondents $(61.66 \%)$ belonged to middle age category and 15.84 per cent were from old age category. Rest of the respondents were in young age category. Gender-wise breakup of the respondents reveals that a large majority of them were male $(97.50 \%)$ and rest of the respondents were female $(02.50 \%)$. It appears that the society here follows patriarchal system i.e. males earn for the family and females take care of the household responsibilities. Besides, most of farmers who visited farmers fair were males, while a very small number of females visits the farmers fair. We need to find out as to why less number of females visits the farmers fair.

Further, the results regarding the educational level of the respondent shows that 34.17 per cent were educated up to primary school level followed by those who were Illiterate (21.66 $\%), 15.84$ per cent were High school and $12.50 \%$ are Middle level, 09.17 per cent were Intermediate level. Only 06.66 per cent of respondents were graduate and above. As regards 90.83 per cent were involved in primary occupation (Farming), 09.17 per cent had involved in primary as well as secondary occupation. Analysis of Family income revealed that 49.16 percent were from medium income group, 28.33 per cent were from high 
income group, and only 22.50 per cent respondents were from low income group.

It also revealed that the family characteristics of the respondents. The findings clearly indicate that 60.83 per cent of the respondents belonged to nuclear family and 39.17 per cent of the respondents belonged to joint family. As regards the distribution of the respondents according to family size, 44.16 per cent of the respondents belonged to small family, 40.00 per cent of the respondent's belonged to medium family, and 15.84 per cent of the respondents belonged to large family.

As regards to house type, a large majority of respondents $(49.16 \%)$ had pucca house, and 36.67 per cent had mixed house and $14.17 \%$ had kaccha houses, each. It is evident from the above table that maximum numbers $(42.50 \%)$ of respondents were small farmers whereas 26.67 per cent were marginal farmers, and 19.16 percent were medium farmers and 11.67 per cent were large farmers.

As regards the type of farming, majority $(67.50 \%)$ was involved in commercial farming and only 32.50 percent were involved in subsistence farming.

Mobile phone is now technology of choice of the masses. The mobile has become a necessity for all types of people irrespective of class or place of residence. The data regarding the ownership and use of mobile phone among the farmers is given in table 2. It is evident that a large majority of the farmers (86.66 per cent) owned mobile phone and only 13.34 per cent did not have a mobile phone. Further, the distribution of respondents according to the type of mobile handset owned and services used by farmers is given in the table 3. Mobile handsets manufactured by various companies are being used by different people according to the choice of features available and their paying capacity.
It is clear from table 3 that 27.50 percent of the farmers had Samsung mobile handset followed by other mobile phones $(20.00 \%)$, Redmi and Reliance jio (13.33\%), Moto $(09.16 \%)$ and Vivo (05.83 \%). Majority of the respondents $(24.16 \%)$ have been using the mobile during the last three years. Further, about 36.67 per cent of the respondents were found to be using mobile services provided by AIRTEL and 25.00 per cent used service of IDEA. 15.83 per cent respondents were found to be using the services provided by BSNL, $15.00 \%$ were using $\mathrm{JIO}$ service and at last 07.50 per cent were using VODAFONE service. Thus, it can be concluded that Samsung mobile handset is very popular among the farming community and they prefer to use the mobile services provided by AIRTEL.

People keep and use mobile for a variety of purposes. The respondents were asked to indicate the purpose of mobile phone usage, constraints in its use and trustworthiness of the information received through mobile. The results obtained are presented in table 4. Majority of respondents $(96.66 \%)$ reported that they use mobile to remain in touch with their family members whereas 80.83 per cent told that they keep the mobile phones for maintaining relations with friends and relatives; 59.16 per cent used the mobile phones for contact with Extension Personnel and only 68.33 per cent used it to contact agricultural input agencies As regards the credibility of information received through mobile phone, only 50.84 per cent trust the information to some extent whereas 40.00 per cent of the respondents reported to trust it to a great extent', and about 09.16 per cent 'do not trust at all'. Further, most of the respondents (i.e. $64.16 \%$ ) faced signal problem while using mobile phone. About 25.84 per cent of the respondents could not pay for mobile used. Rest i.e. 10.00 per cent faced other constraints such as language and voice problems etc. 
Int.J.Curr.Microbiol.App.Sci (2019) 8(8): 2923-2930

Table.1 Distribution of the respondents on the basis of socio economic profile

Age

1. Young (up to 35 years)

2. Adult (36-55 years)

3. Old (above 55 years)

B.

$$
\text { Gender }
$$$$
\text { 1. Male }
$$

2. Female

C. Education

2. Primary

3. Middle

4. High school

5. Intermediate

6. Graduate and above

D. Respondent occupation*

$\begin{array}{ll}1 . & \text { Farming } \\ 2 & \text { Other: Agric. labour, business, }\end{array}$

Frequency Percentage

Family income 1. Low income

(10,000-50,000 per year)

2. Medium income

(50,000-1,00000 per year)

3. High income

F. Family type

(1,0000-10,00000 per year) $\quad 34 \quad 28.33 \%$

2. Joint family

G. Family size
1. Small family

( $<5$ members)

2. Medium family

(5-10 members)

3. Large family

$(>10$ members $)$

H. Type of house

1. Kaccha

2. Pucca

3. Mixed

Size of landholding

1. Less than 2.5 acres

(Marginal farmer) $\quad 32 \quad 26.67 \%$

2. 2.5 to 5.0 acres

(Small farmer) $\quad 51 \quad 42.50 \%$

3. 5.0 to 10 acres

(Medium farmer) $23 \quad 19.16 \%$

4. Above 10 acres

$\begin{array}{lll}\text { (Large farmer) } & 14 & 11.67 \%\end{array}$

2. Type of farming

1. Subsistence type

$39 \quad 32.50 \%$

2. Commercial type

$81 \quad 67.50 \%$

(* More than one response was allowed in case of certain variables)

Table.2 Distribution of the respondents according to mobile phone ownership

\begin{tabular}{lcccc}
\hline S1. No. Mobile phone ownership & Yes & $\%$ & No & $\%$ \\
\hline 1. Own a mobile phone & 104 & 86.66 & 16 & 13.34
\end{tabular}

Table.3 Distribution of respondents according to type of handset and service used.

(N=120)

\begin{tabular}{|c|c|c|c|}
\hline S1. No. & Mobile Phone & Frequency & Percentage \\
\hline 1. & Handsets Owned & & \\
\hline a. & Lenovo & 13 & $10.83 \%$ \\
\hline b. & Redmi & 16 & $13.33 \%$ \\
\hline c. & Samsung & 33 & $27.50 \%$ \\
\hline d. & Reliance Jio & 16 & $13.33 \%$ \\
\hline e. & Vivo & 07 & $05.83 \%$ \\
\hline f. & Moto & 11 & $09.16 \%$ \\
\hline g. & Others & 24 & $20.00 \%$ \\
\hline 2. & Using mobile since when & & \\
\hline a. & 1 year & 21 & $17.50 \%$ \\
\hline b. & 2 year & 26 & $21.65 \%$ \\
\hline c. & 3 year & 29 & $24.16 \%$ \\
\hline d. & 4 year & 25 & $20.87 \%$ \\
\hline e. & 5 year & 19 & $15.82 \%$ \\
\hline 3. & Services Providers & & \\
\hline a. & BSNL & 19 & $15.83 \%$ \\
\hline b. & AIRTEL & 44 & $36.67 \%$ \\
\hline c. & IDEA & 30 & $25.00 \%$ \\
\hline e. & $\mathrm{JIO}$ & 18 & $15.00 \%$ \\
\hline f. & VODAFONE & 09 & $07.50 \%$ \\
\hline
\end{tabular}


Table.4 Distribution of the respondents according to mobile phone usage

$(\mathrm{N}=120)$

\begin{tabular}{lrr} 
Sl. No. Mobile phone & Frequency & Percentage \\
\hline 1. & Purpose of keeping mobile* & \\
a. Contact with Family members & 116 & $96.66 \%$ \\
b. Contact with Friends and Relatives & 97 & $80.83 \%$ \\
c. Contact with Extension Personnel & 71 & $59.16 \%$ \\
d. Contact with Agri-input Agencies & 82 & $68.33 \%$ \\
2. Trust the Information & & \\
a. To a great extent & 48 & $40.00 \%$ \\
b. To some extent & 61 & $50.84 \%$ \\
c. Not at all & 11 & $09.16 \%$ \\
3. Constraints in using Mobile Phone & & \\
a. Signal Problem & 77 & $64.16 \%$ \\
b. Tariff/ Cost of Mobile use & 31 & $25.84 \%$ \\
c. Others & 12 & $10.00 \%$ \\
\hline
\end{tabular}

Table.5 Distribution of the respondents on the basis of expected Services

$$
(\mathrm{N}=120)
$$

\begin{tabular}{lrrrrr} 
Sl. No. Services by KVK, Periyavaram & Yes & $\%$ & No & $\%$ \\
\hline 1. & Receiving Agriculture and related & 103 & 85.84 & 17 & 14.16
\end{tabular} information on mobile

Table.6 Distribution of the respondents on the basis of topics expected $(\mathrm{N}=120)$

Sl. Expected Services through mobile Frequency Percentage No.

\begin{tabular}{llll}
\hline a. & Crop Variety recommended/appropriate & 64 & 53.33 \\
b & Sowing Time & 39 & 32.50 \\
c. Agronomic Practices & 49 & 40.80 \\
d. Seed Treatment & 21 & 17.50 \\
e. Disease Identification and & 87 & 72.50 \\
& Control Measures & & \\
& Fertilizer Applications: Dose, Method \& & & \\
f. Time & 19 & 15.83 \\
g. Harvesting Time & 17 & 14.16 \\
h. Post- Harvest Operations & 22 & 18.33 \\
i. Marketing & 14 & 11.66
\end{tabular}

Table.7 Distribution of the respondents on the basis of willingness to pay

$\begin{array}{lccccc} & & & & & (\mathrm{N}=120) \\ \text { si. No. } & \text { Payment tor IIobile Services } & \text { yes } & \% & \text { No } & \% \\ \text { a. } & \text { Less than } 100 \text { p.m. } & 82 & 68.34 & 38 & 31.66 \\ \text { b. } & 100-200 \text { p.m. } & 67 & 55.83 & 53 & 44.17 \\ \text { c. } & 200-300 \text { p.m. } & 21 & 17.50 & 99 & 82.50\end{array}$

The findings of the study indicate that the majority of the respondents $(50.84 \%)$ trusted the information received through mobile phones to some extent; 40.00 per cent trusted the information to great extent and only 09.16 per cent respondents did not trust the information obtained through mobile phone. Martin and Abbott (2000) in a study on Use of Mobile Phones in Agriculture Development in Uganda reported that more than half of the farmers were using their mobile phones for coordination for access to agricultural inputs, getting market information, monitoring financial transactions and agriculture emergency situations. Slightly less than half were consulting with experts via 
mobile phones. Thus we may safely conclude that information received through mobile phone are perceived by the farmers to be trustworthy.

Use of mobile telephony has increased substantially, thanks to the gradual and regulated expansion of telecommunication services in the country. The people living in urban as well as rural areas have access to one or more mobile services. The farmers are also reportedly using the mobile phones for a variety of purposes. It is yet to be established as to what extent the farmers would be willing to use and pay for getting the information regarding agriculture through mobile (i.e. agriculture information through mobile phone). Many public sector as well as private service institutions has started providing mobile based advisory services to farmers. The respondents were asked to indicate whether they would use such services if started by KVK Periyavarm in future. The results obtained are given in table 5 .

It is clear that a majority $(85.84 \%)$ of the farmers expressed that they would be willing to receive the information (in form of message alerts regarding agriculture) by KVK Periyavaram through mobile phones whereas 14.16 per cent said that they did not want such services. Thus there exists a clear indication for KVK Periyavaram to initiate the mobile advisory services as per the demand of farmers. The areas to be covered under the mobile services remain a concern for the planners as well as policy makers. The results obtained from the present study have indicated the expectations of farmers which are given in table 6.

If KVK Periyavaram ever plans to start the mobile based advisory services for farmers in future, about 72.50 per cent of the respondents told that they would prefer receiving information about disease identification and control measures. This was followed by information about Crop Variety recommended/appropriate $(53.33 \%)$ and about Agronomic Practices (40.80 \%). Further, about 32.50 per cent of the respondents reported to be ready to receive the information regarding Sowing Time followed by Post-Harvest Operations (18.33 $\%)$ and Seed Treatment (17.50\%), Fertilizer Applications (15.83\%) and Marketing (11.66 $\%)$. Additionally, the respondents were also asked as to how much they would be willing to pay for such services. The results obtained are given in table 7 .

It is clear from the above table that about 68.34 percent farmers said that they would be ready to pay less than ` 100 per month for any such mobile service, whereas 31.66 percent said that they can't pay that much. Further, when asked whether they can pay ' 100 to 200 per month, only 55.83 per cent said yes and 44.17 percent said no; and regarding ' 200300 per month, only 17.50 per cent agreed to pay and 82.50 per cent did not agree to pay that much amount for information through mobile phones. This difference may be associated with the difference in land holding pattern as well as annual income of the farmers. However, what is noteworthy is the pattern of farmers willing to pay. If and when such service is started by KVK Periyavaram, the farming community may support the initiative if it is found to be useful and trustworthy.

The study intended to assess the usage pattern and potential of mobile phone to provide agriculture related information to the farming community. The findings clearly show that a large majority of farmers own and use the mobile for a variety of purposes. Farmers are capable and open to use mobile phones for receiving a variety of information. In addition, mobile phones are also being used for agricultural marketing, to obtain 
agriculture credit, etc. The use of mobile phone technology is still in nascent stage. To enhance the use of mobile phones by the farmers especially those belonging to low income groups, there is need to subsidize the cost aspects related to mobile services. Further, there is a need to develop a comprehensive information base catering to the specific and diverse needs of the farmers. The information provided through mobile must be in local language. Information must be provided in the form of voice messages as the text messages may be a limiting factor to illiterate farmers. They are also willing to receive and pay for such information (by an Institution) although the proportion of those who would be willing to pay is less, thus there exists a huge potential for the use of mobile phones in communicating agriculture related information to the farming community.

The study, although limited to one District of A.P and covered those farmers who visited KVK Periyavaram in 2018, has implications for contemporary agricultural extension system in the country. It builds a strong case for an agricultural institution for initiating mobile based information dissemination system. There is no doubt that mobile phones have penetrated in urban as well as rural areas and the ownership is distributed across various socioeconomic strata. Further, Mobile phone can be used to reach the widely scattered and diverse farming community. It can overcome the constraints of time, space and scarce human resources.

\section{References}

Abraham and Jensen, 2007, Getting Prices Right: Mobile Phone Diffusion, Market Efficiency and Inequality. Paper presented at: Francis Andrianarison Conference 2010, Economic Development in Africa. 21 $1^{\text {st }}-23^{\text {rd }}$ March at Oxford (UK).

Ansari M.A and Neha Pandey, 2003, Assessing potential and use of mobile phones in agriculture: Karnataka Journal of Agricultural Science. 26(3): (388-392).

Donner, (2005), Research Approaches to Mobile Use in the Developing World: A Review of Literature. A paper submitted to: The International Conference on Mobile Communication and Asian Modernities, City University of Hongkong.

Mariscal, J. and Rivera, E., 2006, Mobile Communication in Mexico in the Latin America Context. Information Technologies and International Development, 3, p.41-45.

Martin, B. and Abbott, E., 2000, Development Calling: The Use of Mobile Phones in Agriculture Development in Uganda. Greenlee School of Journalism and Communication, Iowa State University. Vol. 5.

Rizvi, S. M. H., 2010, Livelihood Solutions through Mobile Technology: An Assessment Technical Paper No. 1. Rural Research Centre, Institute of Rural Research and Development (IRRAD), Gurgaon, Haryana (India). (Accessed online, http: www.irrad.org).

Shivappa R. Kanavi, 2014, An Analysis of Kisan Mobile Advisory Service (KMAS) of Krishi Vigyan Kendra. M.Sc (Thesis), UAS Dharwad, Karnataka.

Sulaiman, R. 2003, Agricultural ExtensionInvolvement of Private Sector, National Bank for Agricultural and Rural Development, Mumbai, India

\section{How to cite this article:}

Vinod Naik, D., M. Kavitha and Reddy, R.V.S.K. 2019. A Study on Assessing the Potential and Use of Mobile Phones by Farmers in Nellore District of Andhra Pradesh. Int.J.Curr.Microbiol.App.Sci. 8(08): 2923-2930. doi: https://doi.org/10.20546/ijcmas.2019.807.362 